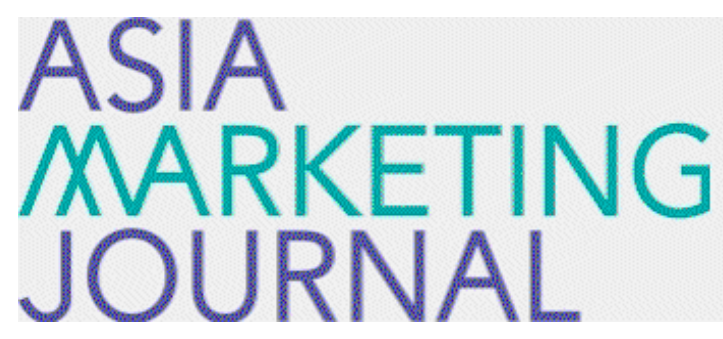

ASIA MARKETING JOURNAL

Volume 23 | Issue 3

Article 3

November 2021

\title{
Social Influence, Xenocentrism and Status Consumption on Purchase Intention: In the Case of Women's Imported Handbags
}

\author{
Munkhbayasgalan Ganbold \\ National University of Commerce and Business, Mongolia \\ Urandelger Gantulga \\ Business School, National University of Mongolia, urandelger@num.edu.mn
}

Follow this and additional works at: https://amj.kma.re.kr/journal

Part of the Advertising and Promotion Management Commons, E-Commerce Commons, Marketing Commons, and the Other Business Commons

\section{Recommended Citation}

Ganbold, Munkhbayasgalan and Gantulga, Urandelger (2021) "Social Influence, Xenocentrism and Status Consumption on Purchase Intention: In the Case of Women's Imported Handbags," Asia Marketing Journal: Vol. 23 : Iss. 3 , Article 3.

Available at: https://doi.org/10.53728/2765-6500.1575

This Article is brought to you for free and open access by Asia Marketing Journal. It has been accepted for inclusion in Asia Marketing Journal by an authorized editor of Asia Marketing Journal. 


\title{
Social Influence, Xenocentrism and Status Consumption on Purchase Intention: In the Case of Women's Imported Handbags
}

\author{
Munkhbayasgalan Ganbold ${ }^{a}$, Urandelger Gantulga ${ }^{\mathrm{b}, *}$

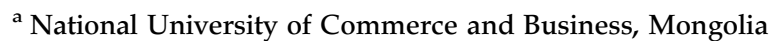 \\ ${ }^{\mathrm{b}}$ Business School, National University of Mongolia, Mongolia
}

\begin{abstract}
The Mongolian market has got filled with imported products that pose a great challenge to domestic businesses. However, on the other hand, exported products give opportunities to understand product quality standards for domestic business owners. Therefore, it becomes meaningful to understand how the consumers distinguish between domestic and imported products. The study examines the relationship between social influence, xenocentrism, status consumption, and imported product's purchase intention. To achieve the purpose of the research, a survey was conducted on consumers who experienced the purchase of imported products. The data were examined using SPSS and SmartPLS 3.3 after a total of 426 effective questionnaires were gathered. The current study reveals social influence and xenocentrism, which were important factors in the purchasing of imported products. Implications of the findings for theory and managerial practice are discussed and future research directions identified.
\end{abstract}

Keywords: Xenocentrism, Status consumption, Social influence, Purchase intention

\section{Introduction}

G lobalization, the social structure, the economy, and the advent of a new era of information technology have all influenced consumer behavior in Mongolia during the previous thirty years. As a consequence, consumers all over the world have greater access to various products from other countries than ever before. Developing countries offer great opportunities for international businesses (Pentz, Terblanche and Boshoff 2017). On the other hand, it has also created some challenges for domestic businesses (Ranjbarian, Rojuee and Mirzaei 2010). To remain in a highly competitive market, domestic businesses need to match the needs of the customer, which is driving business companies to produce high-quality products. Therefore, even domestic businesses in developing countries need to offer world standard products that are equally competitive with international companies. International expansion is a common strategy pursued by companies both to expand their operations and to counteract maturing domestic retail environments (Knight and Kim 2007). According to the findings of the Zahid and Dastane (2016) study on South East Asian (SEA) Young Adults, "Strongest positive correlation occurred between social influence and purchase intension which proves social influence is the most important factor of all which determines purchase intension". Furthermore, it appears that the most commonly used variables in Asian research on factors influencing purchase intention on consumers were social influences (Sharma et al. 2006). Xenocentrism has arisen as a key background in understanding consumer behavior concerning both domestic and imported products on a global scale. Nevertheless, with the growth of global economies, a need for a better understanding of the impact of xenocentrism on consumer behavior has emerged. In the consumer behavior field, studies conclude that consumer xenocentrism refers to a consumers'

Received 17 June 2021; accepted 7 September 2021.

Available online 14 November 2021

* Corresponding author.

E-mail addresses: munkhbayasgalan@nucb.edu.mn (M. Ganbold), urandelger@num.edu.mn (U. Gantulga). 
preference for imported products, rejecting one's domestic products, based on the perception that imported products are superior to domestic ones (Stier 2010) (see Figs. 1 and 2).

Mongolia has made remarkable economic progress over the past 30 years. Its economic structure, the lifestyle of people, and social groups dramatically changed (Asian Development Bank 2020. Mongolia's economic prospects). Consumer status consumption might be changed due to these changes in Mongolia. Therefore, this study was conducted to examine the impact of status consumption on consumer purchasing decisions. Also, the current study aims to fill the gaps present in the existing literature on consumers' need for status consumption and social influence by looking at the imported women's handbags. Studies of status consumption in relation to imported handbags have been undertaken, but not in a context where they have been examined together in developing countries like Mongolia. Sharma et al. (2006) "Asian consumers prefer products made in Western countries". In other words, Mongolian women, like other Asian consumers, are interested in buying products from developed or Western countries. Therefore, importers can focus on staying in the market by providing information on the origin of the product to the target market. The scope of imported products covered in this study was limited to women's handbags for the following reasons. Mongolia has strong comparative advantages in cashmere, leather, and livestock production. Therefore, we chose a women's leather handbag to represent these products, as we believe that it is possible to meet the demand and use of products with comparative advantages domestically and internationally.

The woman handbag is an important durable product in the social life of both developed and developing countries. Women handbag import has increased over the recent years in Mongolia. As of

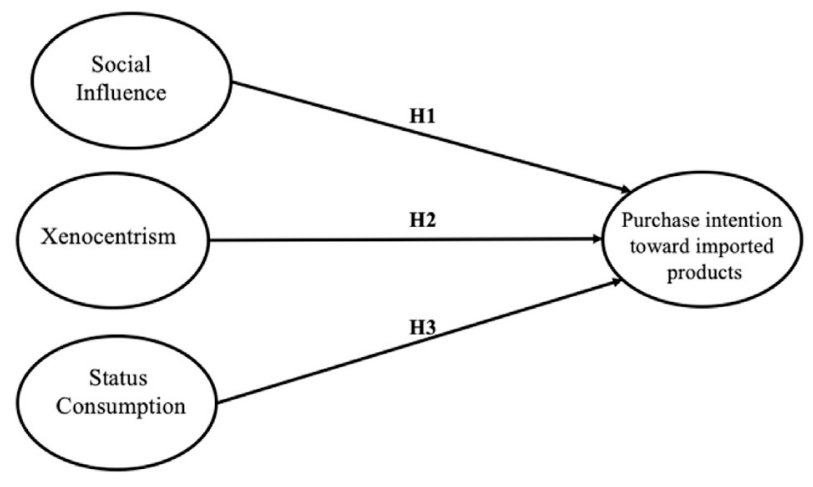

Fig. 1. Proposed model.
2020, 19 companies produce leather bags in Mongolia. In 2020, 1.5 million bags, mobile phone cases, and suitcases were imported, which account for almost two handbags for one woman in Mongolia each year. As mentioned above, imported products pose a great challenge to domestic businesses. To improve the competitiveness of domestic products we need to understand why consumers prefer imported products? What kind of factors influences a consumer's choice? The above statistical information leads to the following reasonable doubts. First, Mongolian leather products have strong comparative advantages. Second, 19 small and medium enterprises domestically produce leather handbags. Third, the consumption of imported handbags is not expected to decrease. These facts present a highly intriguing subject for researchers to explore the consumer purchase intention towards imported products in Mongolia. Moreover, to improve the competitiveness of domestic products, it needs to be investigated what kind of factors play an important role in consumer purchasing behavior toward imported products. The main objective of this research is to answer the following questions:

1. Why do some consumers choose imported products even when domestic ones are qualitatively similar or better and less expensive?

2. How do social influences, xenocentrism, and status consumption influence imported product purchase intention?

To discover how Mongolian consumers' different motivations affect the purchase of imported products, marketers should identify what leads Mongolian consumers to purchase imported handbags and then develop the most effective strategies based on these findings. The results of this study contribute to the marketing area and the body of literature on consumer behavior towards imported handbags. For domestic manufacturers, it provides information to tailor their products to the consumer's demand by taking into consideration the social influence and status consumption that imported products offer.

\section{Theoretical background and hypotheses}

\subsection{Social influence}

Susceptibility to social influence is concerned with complying to the standards or expectations of the group while acquiring things (Bearden, Netemeyer and Teel 1989). The perceived social pressure to follow or not follow the expectations of others' conduct 


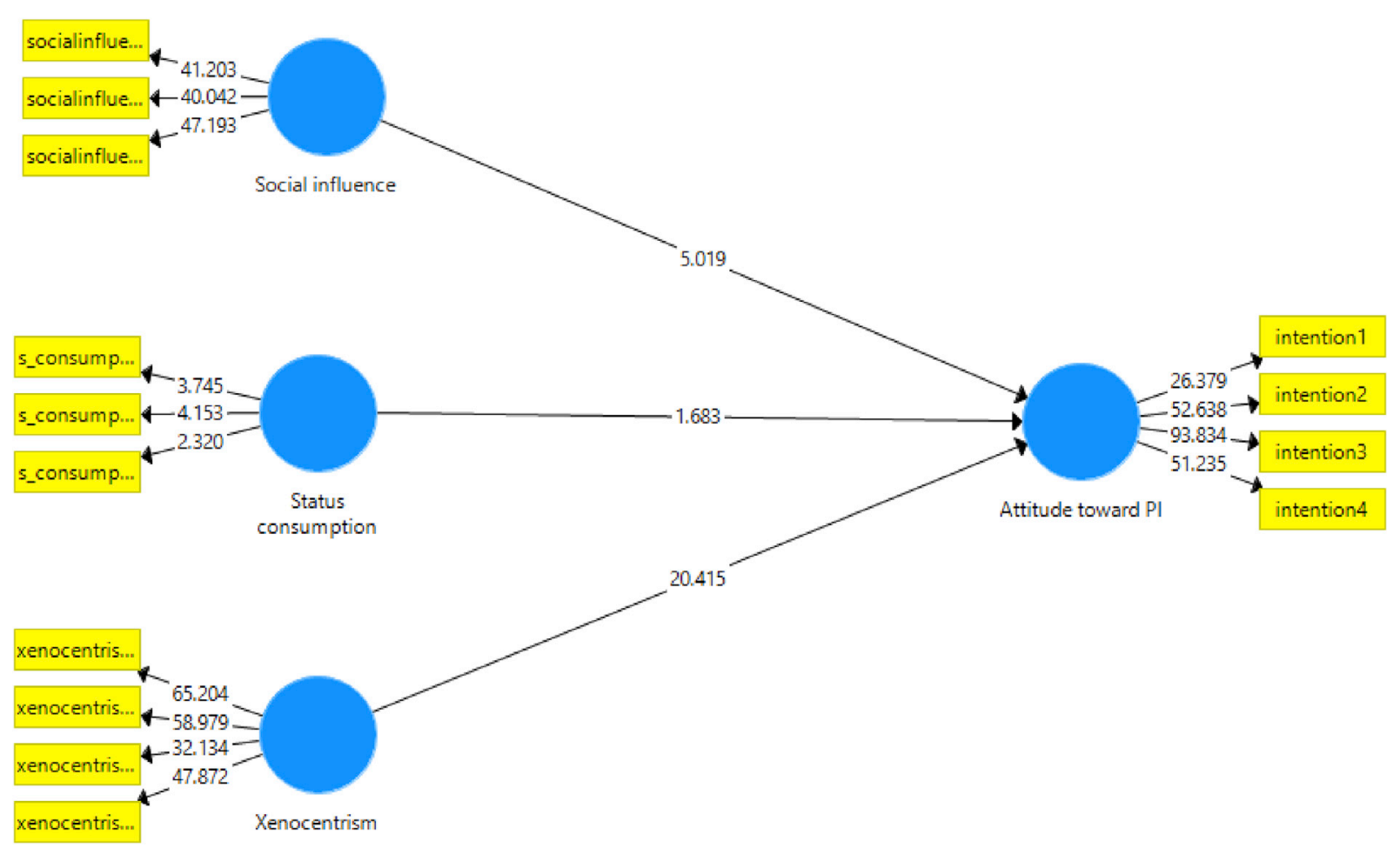

Fig. 2. Research model.

is referred to as social influences (Ajzen 2002). In general, social influence is a powerful predictor of behavior, even if people aren't always conscious of it (Nolan et al. 2008). It entails conforming to the group's conduct and viewpoints (Lin and Huang 2010). Susceptibility to social influence has been suggested as an antecedent for pro-foreign consumer conceptions. Rettanai Kannan (2020) noted Balabanis and Diamantopoulos (2016) empirically tested the relationship between xenocentrism and susceptibility to interpersonal influence (of which normative influence is one dimension) and found the constructs to be positively related. Thus, peer pressure and views held by one's group are associated with xenocentrism. Mueller et al. (2016) in their exploratory study found that peer pressure results in consumers having to display their status through owning foreign products or being xenocentric.

\subsection{Xenocentrism}

Consumer xenocentrism is described as a mindset in which "a person favors products from countries (or regions) other than their own" and "rates things in terms of the other country rather than their own." (Mueller and Broderick 2010).

Xenocentrism is more than just a fondness for the foreign, it is also associated with a rejection of the local (Balabanis and Diamantopoulos 2016; Kent and Burnight 1951). Kent and Burnight (1951) state, Xenocentrics identify with the foreign group and exaggerate the out-group while underestimating their group (Bartsch et al. 2016; Kent and Burnight 1951; Traian-Alexandru 2016). Rejection of in-group is a crucial feature of xenocentrism that distinguishes it from other positive foreign bias notions. Therefore, xenocentrism is most prevalent in developing and transitional countries (Balabanis and Diamantopoulos 2016; Kisawike 2015; Rojas-Méndez and Chapa 2019). In xenocentrism research, "foreign products" relate solely to products from developed countries such as the United States, Western European nations, and Japan (Mueller et al. 2016), not products from other developing countries. In reality, the terms "Western products" and "foreign products" are used interchangeably in existing literature, even though nations investigated, such as Japan, are not Western nations. In summary, "foreign/Western items" denotes things from industrialized countries.

\subsection{Status consumption}

The term "status consumption" refers to consumers who seek self-satisfaction and demonstrate 
prestige and status to others through actual evidence (Eastman et al. 1997) or the motivation process in which a person tries to improve his or her social status through the consumption of products (Eastman, Goldsmith and Flynn 1999). Mason (1992) found substantial levels of status consumption in cultures throughout the world where the utility of things was judged in terms of the social advantages their purchase provided. Status consumption is described as "the motivating process through which individuals attempt to improve their social standing via the conspicuous consumption of commercial goods that signify status both for the individuals and for others around them." As a result, a persistent individual feature, namely the purchase of status goods, may assist the person in their quest for selfrespect and social acceptability. Status-seeking customers are concerned with what relevant groups believe are the greatest options for gaining group status (Clark, Zboja and Goldsmith 2007). The notion of status consumption is used to analyze and assess an individual's proclivity to purchase products and services for the prestige that comes with having such items (Eastman and Goldsmith 1999).

They contend that status consumption is not confined to those with higher incomes and that lowincome consumers also purchase for status. They claim that people consume in this way to get approval from the group and to be a part of it.

This can be linked to consumer xenocentrism when people in developing countries buy imported products in order to imitate and belong to the same group as those in developed countries. It may also refer to people in developing countries who consume imported products in order to be deemed part of the country's higher-income or successful group.

\subsection{Purchase intention}

The term intention refers to the factors that influence and motivate consumers to buy products and services (Hawkins and Mothersbaugh 2010). The intention can represent a person's motivation to carry out an activity (Conner and Armitage 1998). Strong intentions lead to stronger behavior. Purchase intention pertains to the consumer's ability to plan or willing to buy a certain product or service in the future (Chiu et al. 2009). Purchase intention is a plan for future actions or the possibility of believing and acting on that belief. Additionally, purchasing intentions reflect consumers' intentions to buy products or services based on their feelings and attitudes (Engel, Blackwell and Miniard 1995). Studying consumer's purchase intentions is one of the most common methods used by marketers to gain a better understanding of their actual behavior (Ghalandari and Norouzi 2012).

Depending on the above description, purchase intention is defined as the consumer's willingness to buy a particular product based on the needs and requirements of a particular product.

\subsection{Hypotheses development}

\subsubsection{Social influence and purchase intention}

Balabanis and Diamantopoulos (2016) empirically tested social influence and found the constructs to be positively related to the purchase intention. In their exploratory study, Mueller et al. (2016) discovered that social influence causes customers to display their status by acquiring foreign products. According to Foxall, Goldsmith and Brown (1998), customers purchase products not merely to satisfy their hedonic or utilitarian demands, but also to impress their social status. People's purchases affect not only individuals but society as a whole, and they are more likely to be influenced by circumstances or by others than by their own ideas Lee and Park (2018). This demonstrates that people purchase products and services to be accepted by their social surroundings, rather than for themselves.

Furthermore, customers can express themselves by purchasing things that reflect their views (Meixiang and Subin 2021).

Moreover, Wang (2014) has studied the relationship between social influence and purchase intention. The findings suggest that there was a substantial relationship between these two factors. Furthermore, according to Bartels and Onwezen (2014), a consumer's association with a social group is a significant factor on purchase intention. In addition, because it is related to other people, individual decisions have a tremendous impact on the environment (Bertrandias and Elgaard-Gambier 2014). Hence the following hypotheses are proposed:

H1. Social influence positively influences purchase intention

\subsubsection{Xenocentrism and purchase intention}

Xenocentrism was first formed and debated in sociology literature as a counterpoint to Sumner's (1907) xenocentrism idea to define "individuals who prefer a society other than their own and who rate and scale everything in relation to it rather than their own" (Kent and Burnight 1951). Mueller and Broderick (2010) subsequently emphasized the construct's potential relevance for consumer 
research purposes, defining a xenocentric consumer as someone who prefers products from a country other than their own and rates products in reference to the foreign country rather than their own.

Based on above theoretical background, we hypothesize as follows:

H2. Xenocentrism positively influences purchase intention

\subsubsection{Status consumption and purchase intention}

One of the most often discussed subjects in the existing literature is the relationship between status consumption and purchase intention (Balabanis and Diamantopoulos 2016; Rojas-Méndez and Chapa 2019), According to Gaur and Delios (2015), customers like to show their status by patronizing international brands. Consumption of foreign products/brands has been linked to status consumption. As a result, status consumption is likely to have a positive impact on imported products towards purchase intention.

Moreover, the capacity to explain the condition of the product is valued more than the capacity to define their practical qualities. In the buying decision process, it is common for the product's status to take precedence over the functional features of the product (White 2005). That enables consumers to be willing to acquire and even pay a greater price for things with prestige.

Based on above theoretical background, we hypothesize as follows:

H3. Status consumption positively influences purchase intention

\section{Research methodology}

\subsection{Sampling}

In order to achieve research objectives, convenience sampling was used in this study. This study consists of consumers who recently purchased imported handbags in Mongolia. Smart PLS 3.3 was used to evaluate the data (Ringle, Sarstedt and Straub 2012). The data were ruled out if the participants indicated an inappropriate age. Therefore, the target population of this study was women consumers (18-65) who have experienced purchasing imported products, who lived in the Capital city of Mongolia.

\subsection{Data collection procedure}

We developed preliminary measurement items and questionnaires based on previous research literature and then made our appropriate modifications based on the actual environment of this study. This research collected the data from January to February 2021.

The participants were asked to fill out survey questionnaires based on their previous handbag purchases. The survey involves only woman respondents. The decision not to use brand names is meant to ensure that consumer associations with special brands have no bearing on the research results (Thakor and Kohli 1996).

The participants of this study were Ulaanbaatar residents. According to the statistics department, the woman population of Mongolia in 2021 amounted to $1,098,569 .{ }^{1}$ To calculate the sample size, we used the following formula:

$\mathbf{n}=\frac{Z_{a / 2}^{2} \times N \times[\pi \times(1-\pi)]}{\varepsilon^{2} \times(N-1)+Z_{a / 2}^{2} \times[\pi \times(1-\pi)]}$

Here $\mathrm{n}$ is the sample size; $\mathrm{z} \alpha / 2$-the critical value of the standard distribution $=1.96$ with $95 \%$ reliability, $\mathrm{N}-$ the population size; $\pi-0,5, \varepsilon$-the sampling error $5 \%$. The preferred sample size calculated according to this formula was 384 woman consumers.

In this study, a total of 500 samples were collected from Mongolian consumers. After removing invalid questionnaires, there were 426 valid samples. Invalid questionnaires were excluded from the analysis. The effective rates of the collection were $85.2 \%$.

\subsection{Measurements}

The research instrument was translated into the Mongolian language following a standard backtranslation procedure. To verify reliability and validity status, it was pre-tested with a group of graduate students at the National University in Mongolia. There were 15 items used to measure four constructs on a five-point Likert scale. All scales of concepts in the research model are adopted from previous research. Social influence was evaluated by adapting items developed by Hsu and Lin (2008). Furthermore, status consumption was adapted from Eastman, Goldsmith and Flynn (1999). Xenocentrism was estimated by items adapted from Balabanis and Diamantopoulos (2016), Purchase

\footnotetext{
1 "Statistical Yearbook of Mongolia" 2020.
} 
intention to adopt was calculated by using items adapted from Ajzen and Fishbein (1980).

\section{Results}

\subsection{Data analysis procedure}

This study used the social science statistical software packages SPSS 21 and SmartPLS 3.0 to analyze the data. Partial Least Square (PLS) was employed to test the model and hypotheses. Model estimation was performed by SmartPLS 3.0 (Ringle et al. 2013). $\mathrm{t}$-values were calculated using a bootstrapping procedure with 1000 re-samples (Chin 1998). Smart PLS-3 path models have two sets of linear equations: The inner model (structural model) and the outer model (measurement model). The inner model specifies the relationship between unobserved or latent variables, and the outer model specifies the relationships between the latent variable and its observed manifest variable (Henseler, Ringlt and Sinkovics 2009).

\subsection{Measurement model}

The general approach recommended by Gefen, Straub and Boudreau (2000) for evaluating validity and reliability was followed. Convergent and discriminant validity was examined for the assessment of validity. The average variance extracted (AVE) is used as a criterion of convergent validity (Fornell and Larcker 1981). If AVE is more than 0.5, it indicates that the construct has sufficient convergent validity. To measure internal consistency, composite reliability (CR) is used. The value of CR must be higher than 0.7. Our data shows that CR is more than 0.7 and AVE is more than 0.5, so all constructs have convergent validity. Fornell and Larcker (1981) criterion was used to assess discriminant validity. The AVE of each latent variable should be higher than the squared correlations with all other latent variables (AVE $\left.>\varphi^{2}\right)$. Our data shows that all AVE exceed the squared correlation, so all constructs have discriminant validity. Cronbach's alpha and composite reliability are used to measure internal consistency and measure reliability based on the interrelationship of the observed item variables. Table 1 shows that the data are reliable because both Cronbach's alpha and the composite reliability are above 0.6 (Eisingerich and Rubera 2010). The Average Variance Extracted (AVE) measures the convergent validity. The data have adequate convergent validity if the AVE score exceeds 0.5 .

\subsection{Structural model}

As the outer model shows that data is reliable and valid, we can evaluate the inner model. The structural model (inner model) specifies the relations among latent constructs. We tested the significance level of path coefficients with a bootstrapping with 1000 re-samples. Results indicate that all hypotheses are supported. Table 2 shows the results of the hypothesis testing and the PLS structural model. The hypotheses are tested by path coefficients and significance levels. First, the researcher analyses the indirect effect between the independent variable and the intervening variable. An direct relationship exists between the variables if the $t$-value is above 1.96. The results show that SI-PI (5.019) exceeded 1.96, however, SC-PI (1.683) did not exceed 1.96, and XEN-PI (20.415) also exceeded 1.96. The proposed conceptual model is supported by empirical data. The path analysis provides support for all hypotheses in this research. The results of the hypothesis testing are summarized in Table 2 (see Table 3).

\section{Discussion}

The current study was undertaken to examine the effects of consumers' status consumption and social influence on purchase intention by focusing on Mongolian consumers. We specifically tested consumers' status consumption, social influence, and xenocentrism as antecedents of purchase intention towards imported handbags.

Hypotheses 1 predict that social influence has positive impacts on purchase intention. It was found that social influence had a significant and positive effect on purchase intention towards imported handbags. This is in line with a previous study by Tjokrosaputro and Cokki (2020), which also found that social influence had the most significant effect

Table 1. Reliability, convergent and discriminant validity.

\begin{tabular}{|c|c|c|c|c|c|c|c|}
\hline Constructs & Cronbach's Alpha & CR & AVE & (1) & (2) & (3) & (4) \\
\hline Purchase Intention & 0.862 & 0.906 & 0.708 & 1.000 & & & \\
\hline Social Influence & 0.828 & 0.886 & 0.660 & 0.583 & 1.000 & & \\
\hline Status consumption & 0.833 & 0.893 & 0.738 & 0.062 & 0.126 & 1.000 & \\
\hline Xenocentrism & 0.877 & 0.915 & 0.729 & 0.806 & 0.518 & 0.039 & 1.000 \\
\hline
\end{tabular}


Table 2. Path coefficient results.

\begin{tabular}{|c|c|c|c|c|c|}
\hline & Original sample (O) & Sample mean $(\mathrm{M})$ & Standard deviation (STDEV) & T statistics & P-value \\
\hline \multicolumn{6}{|l|}{$\begin{array}{l}\text { Dependent: Purchase } \\
\text { intention }\end{array}$} \\
\hline Social influence & 0.215 & 0.213 & 0.041 & 5.019 & $0.000^{* * *}$ \\
\hline Status consumption & 0.064 & 0.052 & 0.046 & 1.683 & 0.093 \\
\hline Xenocentrism & 0.696 & 0.698 & 0.035 & 20.415 & $0.000^{* * *}$ \\
\hline R2 & & & & & 0.280 \\
\hline $\mathrm{R} 2$ adjustment & & & & & 0.278 \\
\hline
\end{tabular}

on purchase intention. Henceforth, marketers should attempt to create positive social influence for their products in the future. In such cases, one of the most popular methods of increasing social influence is through influencer marketing. At the same time, the data revealed that in the case of Mongolian consumers, xenocentrism does carry a positive effect on the purchase intention towards imported products. Therefore, marketers should consider consumer xenocentrism when making branding decisions (Klein 2002).

According to the findings of the Zahid and Dastane (2016) study on South East Asian (SEA) Young Adults, "Strongest positive correlation occurred between social influence and purchase intention which proves social influence is the most important factor of all which determines purchase intention". Furthermore, it appears that the most commonly used variables in Asian research on factors influencing purchase intention on consumers were social influences (Sharma et al. 2006).

Our research also shows that social influence has a strong and significant influence on the purchasing intention of Mongolian women. Perhaps a common feature of Asian consumer behavior is social influence. Therefore, it may be effective for importers to implement a combination of promotion strategies such as social influencer, social media, buzz marketing, and Word of Mouth (or e-WoM) to introduce their products to the market.

Consumers in developed countries prefer to purchase domestic products while consumers in developing countries prefer products from developed countries (Alden et al. 2013). Research shows that xenocentrism has a significant and positive impact on purchasing intention towards imported handbags. The results of our research were consistent with Sharma et al. (2006) "Asian consumers prefer products made in Western countries". In other words, Mongolian women, like other Asian consumers, are interested in buying products from developed or Western countries. Therefore, importers can focus on staying in the market by providing information on the origin of the product to the target market. Instead, domestic manufacturers should try to gain a competitive advantage from importers by establishing joint ventures with developed or Western handbag manufacturers and becoming their franchisee.

Another Asian example is South Korea, which, in addition to its two neighbors (Russia and China), is one of the top trading partners with Mongolia. Korean products, which are already well-known among Mongolian consumers. Korean products are high quality with affordable price and logistics are well developed compared to Western countries.

Its liberal trade policy has allowed multi-national products to enter the country, giving its people more foreign-made product options than they had ever had before.

South Korea has grown as a major exporter of popular culture since the 21st century, which have become important parts of the country's booming economy. In 2021, South Korea was Mongolia's 4th biggest trade partner following China, Russia and Japan. Apart from 1990, the first year of establishing diplomatic ties, South Korea has recorded a consistent trade surplus with Mongolia. South Korea has had a profound influence on modern culture, music, film production, television and the behavior of people around the world. Mongolians are influenced by Korean culture in a variety of

Table 3. The results of the hypothesis testing.

\begin{tabular}{lll}
\hline & Hypotheses & Results \\
\hline H1 & Social influence has a positive impact on imported products purchase intention & Confirmed \\
H2 & Xenocentrism has a positive influence on imported products purchase intention & Confirmed \\
H3 & Status consumption has a positive impact on imported products purchase intention & Rejected \\
\hline
\end{tabular}


ways, including work, studies, K-pop, Korean dramas, Restaurants, Chain stores (E-mart, CU, GS25) and Cosmetic products. This cultural influence has created a solid foundation for a favorable attitude toward any Korean national brand.

Our study concludes that status consumption does not affect the purchasing intention. Compared to other Asian countries, Mongolia's late transition to a market economy and the recent shift in economic and social ideology, as well as the small differences in social class and social group, may have contributed to this conclusion. Fake and counterfeit versions of luxury handbags are common on the black market, so a marketing strategy for importers to establish an average and public brand can be successful.

This also may be due to the low level of domestic production in Mongolia, the high consumption of imported consumer products, the fact that some imported products are cheaper than domestic production due to its border with China and the majority of consumers do not trust some imported goods.

Perhaps these hypotheses can be confirmed only if we study the purchase intention towards imported luxury brands of handbags from highly developed countries. It will be more effective to conduct more detailed research in these areas in the future.

\subsection{Limitations and future research}

These results contribute to our understanding of both status consumption and social influences on purchase intention. However, the study has certain limitations. One of the circumstances that may have negatively influenced the results is the insufficient number of participants in the present study. Four hundred and twenty-six participants were conducted in Ulaanbaatar city in Mongolia. By increasing the sample size, testing this model extensively, future research could be generalized to critically evaluate the proposed framework. The data was gathered from the capital city of Mongolia, which may not represent the entire population of the country.

Future studies are highly recommended to select a more diversified group of individuals. Moreover, culture also affects consumer behavior differently. Consequently, these can be considered as potential limitations for a future study.

Future research should examine the constructs in terms of demographic or psychographic characteristics. A gender analysis, for example, may demonstrate that men and women consume differently based on their status, social influence and xenocentrism, which could enable a more targeted strategy. Moreover, psychographic segmentation may influence xenocentrism, which could enable a more targeted strategy, thus campaigns that strongly resonate with this target market can be implemented.

\section{Declaration of competing interest}

The Author(s) declare(s) that there is no conflict of interest.

\section{References}

Ajzen, Icek (2002), "Perceived Behavioral Control, Self-Efficacy, Locus of Control and The Theory of Planned Behavior," Journal of Applied Social Psychology, 32 (4), 665-83. https:// doi.org/10.1111/j.1559-1816.2002.tb00236.x

Ajzen, Icek and Martin Fishbein (1980), "Understanding Attitudes and Predicting Social Behavior," Englewood Cliffs, NJ: Prentice-Hall.

Alden, Dana L., James B. Kelley, Petra Riefler, Julie A. Lee, and Geoffrey N. Soutar (2013), "The Effect of Global Company Animosity on Global Brand Attitudes in Emerging and Developed Markets: Does Perceived Value Matter?" Journal of International Marketing, 21 (2), 17-38.

Asian Development Bank (2020), "Mongolia's Economic Prospects Resource-Rich and Landlocked Between Two Giants," Matthias Helble, Hal Hill and Declan Magee, eds. https:// doi.org/10.22617/SGP200172-2. https://www.adb.org/sites/ default/files/publication/611416/mongolia-economicprospects.pdf

Balabanis, George and Adamantios Diamantopoulos (2016), "Consumer Xenocentrism as Determinant of Foreign Product Preference: A System Justification Perspective," Journal of International Marketing, 24 (3), 58-77. https://doi.org/10.1509/ jim.15.0138

Bartels, Jos and Marleen C. Onwezen (2014), "Consumers' Willingness to Buy Products with Environmental and Ethical Claims: The Roles of Social Representations and Social Identity," International Journal of Consumer Studies, 38 (1), 82-9. https://doi.org/10.1111/ijcs.12067

Bartsch, Fabian, Petra Riefler, and Adamantios Diamantopoulos (2016), "A Taxonomy and Review of Positive Consumer Dispositions Toward Foreign Countries and Globalization," Journal of International Marketing, 24 (1), 82-110.

Bearden, William O., Richard G. Netemeyer, and Jesse E. Teel (1989), "Measurement of Consumer Susceptibility to Interpersonal Influence," Journal of Consumer Research, 15 (4), 473-81. Accessed from, https://doi.org/10.1086/209186.

Bertrandias, Laurent and Leila Elgaaied-Gambier (2014), "Others' Environmental Concern as a Social Determinant of Green Buying," Journal of Consumer Marketing, 31 (6/7), 417-29. https://doi.org/10.1108/JCM-05-2014-0966

Chin, Wynne W. (1998), "The Partial Least Squares Approach for Structural Equation Modeling," in Methodology for Business and Management", Modern Methods for Business Research, G.A. Marcoulides, ed. Lawrence Erlbaum Associates Publishers, 295-336.

Chiu, Chao-Min, Chen-Chi Chang, Hsiang-Lan Cheng, and YuHui Fang (2009), "Determinants of Customer Repurchase Intention in Online Shopping," Online Information Review, 33 (4), 761-84. https://doi.org/10.1108/14684520910985710

Clark, Ronald A., James J. Zboja, and Ronald E. Goldsmith (2007), "Status Consumption and Role-Relaxed Consumption: A Tale of Two Retail Consumers," Journal of Retailing and Consumer Services, 14, 45-59.

Conner, Mark and Christopher J. Armitage (1998), "Extending the Theory of Planned Behavior: A Review and Avenues for 
Further Research," Journal of Applied Social Psychology, 28 (15), 1429-64. https://doi.org/10.1111/j.1559-1816.1998.tb01685.x

Eastman, Jacqueline K., Bill Fredenberger, David Campbell, and Stephen Calvert (1997), "The Relationship Between Status Consumption and Materialism: A Cross-Cultural Comparison of Chinese, Mexican, and American Students," Journal of Marketing Theory and Practice, 5, 52-66.

Eastman, Jacqueline K., Ronald E. Goldsmith, and Leisa Reinecke Flynn (1999), "Status Consumption in Consumer Behavior: Scale Development and Validation," Journal of Marketing Theory and Practice, 7 (3), 41-52. Retrieved June 14, 2021, from http://www.jstor.org/stable/40469967.

Eisingerich, Andreas B. and Gaia Rubera (2010), "Drivers of Brand Commitment: A Cross-National Investigation," Journal of International Marketing, 18, 64-79.

Engel, James, Roger D. Blackwell, and Paul W. Miniard (1995), Consumer behavior. Fort Worth: Dryden Press.

Fornell, Claes and David F. Larcker (1981), "Evaluating Structural Equation Models with Unobservable Variables and Measurement Error," Journal of Marketing Research, 18 (1), 39-50. https://doi.org/10.2307/3151312

Foxall, Gordon R., Ronald E. Goldsmith, and Stephen Brown (1998), "Consumer Psychology for Marketing," London: Int. Thomson Business Press.

Gaur, Ajai and Andrew Delios (2015), "International Diversification of Emerging Market Firms: The Role of Ownership Structure and Group Affiliation," Management International Review, 55, 235-53. https://doi.org/10.1007/s11575-015-0240-0

Gefen, David, Detmar Straub, and Marie-Claude Boudreau (2000), "Structural Equation Modeling and Regression: Guidelines for Research Practice," Communications of the Association for Information Systems, 4. https://doi.org/10.17705/ 1CAIS.00407. Article 7.

Ghalandari, Kamal and Abdollah Norouzi (2012), "The Effect of Country of Origin on Purchase Intention: The Role of Product Knowledge," Research Journal of Applied Sciences, Engineering and Technology, 4, 1166-71.

Hawkins, Del I. and David L. Mothersbaugh (2010), "Consumer Behavior: Building Marketing Strategy"/Del I. Hawkins," David L. Mothersbaugh.

Henseler, Jörg, Christian M. Ringle, and Rudolf R. Sinkovics (2009), "The Use of Partial Least Squares Path Modeling in International Marketing," in New Challenges to International Marketing, R.R. Sinkovics and P.N. Ghauri, eds. Vol. 20, pp. 277-319. https://doi.org/10.1108/S1474-7979(2009)0000020014. Advances in International Marketing.

Hsu, Chin-Lung and Judy Chuan-Chuan Lin (2008), "Acceptance of Blog Usage: the Roles of Technology Acceptance, Social Influence and Knowledge Sharing Motivation," Information and Management, 45 (1), 65-74. https://doi.org/10.1111/j.15591816.1998.tb01685.x

Kent, Donald and Robert G. Burnight (1951), "Group Centrism in Complex Societies," American Journal of Sociology, 57 (3), 256-9. Retrieved August 5, 2021, from http://www.jstor.org/stable/ 2771646.

Kisawike, Blandina (2015), "How Country of Origin, Consumer Ethnocentrism and Consumer Xenocentrism Impact Upon Risk and Involvement in the Malaria Medication Decision Making Process in Tanzania."

Klein, Jill Gabrielle (2002), "US Versus Them, or Us Versus Everyone? Delineating Consumer Aversion to Foreign Goods," Journal of International Business Studies, 33 (2), 345-63.

Knight, Dee K. and Eun Young Kim (2007), "Japanese Consumers' Need for Uniqueness: Effects on Brand Perceptions and Purchase Intention," Journal of Fashion Marketing and Management, 11 (2), 270-80. https://doi.org/10.1108/13612020710751428

Lee, Hyun Ju and Seong-Yeon Park (2018), "Consumer Values and Green Consumption: Implications for Marketing Strategy and Environmental Policy," Asia Marketing Journal, 19 (4), 87-114.

Lin, Tung-Ching and Chien-Chih Huang (2010), "Withholding Effort in Knowledge Contribution: The Role of Social Exchange and Social Cognitive on Project Teams," Information Manager, 47, 188-96.
Mason, Roger (1992), "Modelling the Demand for Status Goods," Association for Consumer Research Proceedings, 88-95.

Meixiang, Cui and Im Subin (2021), "The Impact of Conspicuous Consumption and Perceived Value on New Product Adoption Intention," Asia Marketing Journal, 23 (1), 63-94.

Mueller, Rene and Amanda J. Broderick (2010), "Consumer Xenocentrism. An Alternative Explanation for Foreign Product Bias," in Proceedings of Annual Hawaii International Business Research Conference. Honolulu, Hawaii. Australia: World Business Institute, 27-8.

Mueller, Rene Dentiste, George Xun Wang, Guoli Liu, and Charles Chi Cui (2016), "Consumer Xenocentrism in China: An Exploratory Study," Asia Pacific Journal of Marketing \& Logistics, 28 (1), 73-91.

Nolan, Jessica M., P. Wesley Schultz, Robert B. Cialdini, Noah J. Goldstein, and Vladas Griskevicius (2008), "Normative Social Influence is Underdetected," Personality and Social Psychology Bulletin, 34 (7), 913-23. https://doi.org/10.1177/0146167208316691

Pentz, Chris, Nic S. Terblanche, and Christo Boshoff (2017), "Antecedents and Consequences of Consumer Ethnocentrism: Evidence from South Africa," International Journal of Emerging Markets, 12 (2), 199-218. https://doi.org/10.1108/IJoEM-092015-0189

Ranjbarian, Bahram, Morteza Rojuee, and Abbas Mirzaei (2010), "Consumer Ethnocentrism and Buying Intentions: An Empirical Analysis of Iranian Consumers," European Journal of Social Sciences, 13 (3), 371-86.

Rettanai Kannan, D. (2020), "Consumer Xenocentrism: Antecedents, Consequences (and Moderators) and Related Constructs," Thesis (Ph.D.) Carleton University 2020.

Ringle, Christian M., Marko Sarstedt, Rainer Schlittgen, and Charles R. Taylor (2013), "PLS Path Modeling and Evolutionary Segmentation," Journal of Business Research, Elsevier, 66 (9), 1318-24.

Ringle, Christian M., Marko Sarstedt, and Detmar W. Straub (2012), "Editor's Comments: A Critical Look at the Use of PLSSEM in "MIS Quarterly," MIS Quarterly, 36 (1), Iii-Xiv. https:// doi.org/10.2307/41410402

Rojas-Mendez, Jose and Sindy Chapa (2020), "X-Scale: A New Scale to Measure Consumer Xenocentrism," Marketing Intelligence \& Planning, 38 (3), 354-68. https://doi.org/10.1108/MIP01-2019-0062

Sharma, Piyush, C.M.Y. Chung, Krishna Erramilli, and Bharadhwaj Sivakumaran (2006), "Challenges of Marketing to Asian Consumers: Exploring the Influence of Different Cultures, Lifestyles and Values on Consumer Behaviour in Asia."

Stier, Jonas (2010), "The Blindspots and Biases of Intercultural Communication Studies: A Discussion on Episteme and Doxa in a Field," Journal of Intercultural Communication. Retrieved from http://urn.kb.se/resolve?urn=urn:nbn:se:du-20717.

Sumner, William Graham (1907), "Folkways: A Study of the Sociological Importance of Usages, Manners, Customs, Mores and Morals," Ginn.

Thakor, Mrugank V. and Chiranjeev Kohli (1996), "Brand Origin: Conceptualization and Review," Journal of Consumer Marketing, $13(3), 27+$.

Tjokrosaputro, Miharni and Cokki Cokki (2020), "The Role of Social Influence Towards Purchase Intention with Value Perception as Mediator: A Study on Starbucks Coffee as an Environmentally Friendly Product.'

Traian-Alexandru. (2016), "Ethnocentrism - the Danger of Cultures' Collision," International Journal of Interdisciplinary Scientific Research, 2 (4), 101-5.

Wang, Shih-Tse (2014), "Consumer Characteristics and Social Influence Factors on Green Purchasing Intentions," Marketing Intelligence \& Planning, 32 (7), 738-53.

White, Tiffany Barnett (2005), "Consumer Trust and Advice Acceptance: The Moderating Roles of Benevolence, Expertise, and Negative Emotions," Journal of Consumer Psychology, 15, 141-8.

Zahid, Abdul and Omkar Dastane (2016), "Factors Affecting Purchase Intention of South East Asian (SEA) Young Adults Towards Global Smartphone Brands," ASEAN Marketing Journal, VIII (No. 1), 66-84. Available at: SSRN: https://ssrn.com/ abstract $=2809448$. 